\title{
Saving Employee Engagement: Emergent Strategies in Response to Externally Mandated Change
}

\author{
Matthew Vanschenkhof ${ }^{1}$, Matthew Houseworth ${ }^{2}$, Lorin Walker ${ }^{2}$ and Scott Smith ${ }^{2}$ \\ ${ }^{1}$ Applied Human Sciences - Hotel, Restaurant, \& Tourism Management, Western Kentucky University, Bowling Green, Kentucky, \\ USA \\ ${ }^{2}$ Division of Business Strategy, University of Central Missouri, Warrensburg, Missouri, USA \\ *Correspondence: Scott Smith, sdsmith@ucmo.edu
}

\begin{abstract}
This study discusses critical strategic factors associated with concerns over implementation of the Fair Labor Standards Act (FLSA) mandate of December 2016. Emergent Human Resources (HR) strategies developed by human resource managers were investigated, as well as how these managers influenced issues directly linked with employee engagement, communication, employee status, and organizational responses. Interviews were facilitated less than four months prior to the mandate's implementation. Investigators found the FLSA mandate created concerns for human resource managers based on current organizational practices, compensation, and bonus structures, as well as employee morale challenges. Specific findings included a desire for organizational communication concerning changes due to the mandate, but a universal lack of strategic planning or implementation of a process to preserve employee engagement. Further, HR management concerns regarding employee morale and consequent action were investigated, as a change in status from exempt to non-exempt would be perceived as a demotion by most employees. This research finds that the ability to communicate changes with constituents, help manage implementation for HR employees, care for morale and cultural repercussions, and demonstrate fairness in compensation are critical factors to consider for a large-scale change and implementation in HR policy due to sweeping regulatory changes.
\end{abstract}

Keywords: Employee engagement, Communication, Fair Labor Standards Act, Employee morale, Emergent strategy

\section{ARTICLE INFORMATION}

Author(s): Matthew Vanschenkhof, Matthew Houseworth, Lorin Walker and Scott Smith

Received: 19 May, 2021; Accepted: 22 June, 2021; Published: 30 June, 2021; e-ISSN: 2347-4696;

Paper Id: BMN-IJBMR-2021-43;

Citation: $10.37391 /$ IJBMR.090214

Webpage-link:

\begin{tabular}{l} 
CrOSSOF mef mber \\
\hline CROSSREF.ORG \\
THECITATION LINIING BACKBONE
\end{tabular}

https://ijbmr.forexjournal.co.in/archive/volume-9/ijbmr-090214.html

\section{INTRODUCTION}

Dave Ulrich states "change has a way of scaring people scaring them into inaction" in his discussion of human resource department management [1]. We know that rapid changes are among the most important challenges for organizations [2]. Environmental or external pressure to change is extremely important to organizations, and the change and their speeds are critical to maintaining efficient functionality [3]. We examined how a sample of organizations chose to respond in the face of externally driven change, in this case initiated by government regulatory requirements. We compared their actual responses, or strategies, to three predicted responses that were derived from the existing change management literature. These predicted responses were seen as what organizations might be expected to do in the event of imposed change. In summary, these responses include: 1) enrolling internal stakeholders by consistently applying past relevant experience regarding change, 2) creating a critical mass of consensus by rigorously overseeing communication, and 3) generating social capital by tightly managing leadership trust. We particularly focused on how these responses might impact employee engagement, as investigated by
VanSchenkhof, et al. [4]. Specifically, eight human resource managers were interviewed to determine primary concerns and responses associated with organizational change stemming from implementation of the Fair Labor Standards Act (FLSA). McCraken's process of analysis was used to understand the predominant concerns and actions associated with mitigating potential ill effects on employee engagement.

In recent years, the HR function in organizations has been encouraged to evolve significantly to become a strategic business partner and to handle the challenges of major changes in political, technological, and workforce environments. Organizational change researchers have described HR roles as transitioning from typically "operational, administrative, functionally oriented, and reactive," to more "strategic, consultative, business-oriented, and proactive" [5]. Further, Henson [6] asserts that HR professionals must continue to make the critical shift from stereotypical HR labels of "record keeper" or "administrator" to becoming a fundamental "strategic business partner" for their respective organizations, by embracing and defining themselves as a "core organizational infrastructure," viewing employees as "highlyvalued assets," and implementing best practices associated with their function.

This paper examined literature-based strategies predicting how HR professionals will behave in their role as strategic partners. These actions were compared to actual accounts of HR actions, often called emergent strategies. Emergent organizational strategies have been described by McKeown [7] as "a mixture of what is planned and what is done". Emergent strategies are often theory-driven but are usually also expeditious and need-driven. Both strategies can be effective; 
indeed, the combination of the two often results in newer, adaptive, more effective actions. In time, emergent strategies can become widely accepted, highly useful strategies. We used grounded research methodology to examine extant emergent strategies in this arena. We examined strategies across the organization. However, the FLSA mandate was expected to most directly affect front-line and lower-level manager compensation and benefit structures, which in turn would affect employee engagement. As expected, we found HR managers were often concerned with the FLSA mandate's impact on employee engagement and how to take action to mitigate potential negative impacts.

To successfully navigate the challenges and complexities posed by a world of constant change, HR researchers and practitioners alike are challenged to take actions to assist organizations accomplish three objectives [8]. First, companies must realize cost effectiveness through substantial cost reduction associated with the services they provide (considered the operational driver). Next, they must streamline and enhance their services to meet the expectations of executives, mid-level and line managers, as well as regular employees (considered the relational driver). Finally, companies must ultimately achieve and facilitate the strategic objectives of the organization (considered the transformational driver) [8]. Arrowsmith \& Parker [9] further argue that appropriate HR actions such as these create a "business partner relationship with management...best served by an evidencebased approach in which [employee engagement] is articulated to management as a means to improve cost, revenue and/or quality as well as an important goal in its own right". Accomplishment in these three areas enables HR to gain credibility and freedom to implement a wide range of strategies.

As an illustrative example of how HR might assist organizations to meet these objectives, we compared the predicted responses to the challenges imposed by the proposed Fair Labor Standards Act (FLSA) status changes for the exempt employee compensation threshold, with the actual responses. To provide a brief account of the proposed FLSA mandated change; The United States Department of Labor proposed that the exempt salary threshold would increase from $\$ 455$ to $\$ 913$ per week for annual compensation of $\$ 47,476$ [10]. The FLSA's proposed changes originated in 2014 with President Barack Obama proposing a rule change to increase the exempt minimum salary threshold via a regulatory rule [11]. The final rule was issued through the Department of Labor in May of 2016 with a start date of December 1, 2016. Implementation was imminent. However, at the last minute, a federal district court in Texas issued an injunction in November of 2016, staying implementation upon an appeal. This same court invalidated the FLSA regulations in late August of 2017 [12]. Due to this legal battle, the proposed changes to the FLSA have not as yet been fully implemented, but the threat of impending rule changes did markedly affect the strategic approaches of HR organizations as they prepared and took proactive action in anticipation.

\section{LITERATURE REVIEW}

\subsection{Employee Engagement}

Following the research of W.A. Kahn [13] in personal engagement, Maslach, et al. [14] were among the first researchers to address employee engagement and its impact on the work environment. Maslach, et al. [14] defined employee engagement as "a persistent positive affective state, characterized by high levels of activation and pleasure" and the "positive antithesis to job burnout". Furthermore, Shuck \& Wollard [15] noted that both Kahn [13] and Maslach, et al. [14] provided the first conceptual literature to not only define but attempt to understand employee engagement. Employee engagement is the extent an employee is focused on their within-role responsibilities [16]. This also includes how the employee views their fit and commitment to behaviors associated with task completion within their current role [13]. We have seen the important connection between employee engagement and human resource management issues [17, 18]. The degree of employee engagement has been found to be positively correlated with traditional business measures, such as higher return on assets, better performance, and sales growth and lower absenteeism, according to Harter, et. al., [19], Salanova, et. al., [20] \& Towers Perrin, [21]. In addition, Rynes, et al. [22] found that monetary incentives had a strong effect on employee engagement. Moreover, it has been found that money is the strongest motivational driver when increasing productivity and, in essence, engagement of employees [23]. In the case of this research study, the impending implementation of the FLSA mandate required HR managers and organizations to determine how to meet the mandate's guidelines regarding an individual's compensation. Therefore, any monetary action by HR was expected to influence an employee's engagement.

VanSchenkhof, et al. [4] discuss employee engagement as including three aspects of an employee's perception of factors within their role: pay and prestige, productivity impact, and influencers beyond pay (benefits, hours, etc.). Within the context of this study, the focus is more specifically on how a change in pay may impact employee engagement.

Saks [16] asserts that when an employee believes their organization is not providing adequate resources that they are more likely to disengage from their responsibilities. This phenomenon would be of great concern to the HR managers discussed in this study, as the FLSA mandate is most commonly associated with supervisory line-level or front-line managers. Any change in the engagement of this level of management would have a disproportionate impact on employee attitude and engagement, given their direct contact with the workforce. A supervisor disengaging, even moderately, may have serious financial and/or performance effects on an operation.

\subsection{Emergent Strategy}

Winston Churchill once quipped, "However beautiful the strategy, you should occasionally look at the result." Strategy can sometimes unfold in unplanned ways. A strategic organization is considered to define direction and plan a 
process that follows the intentions of the organization. However, the reality in organizations sometimes unfolds differently. Mintzberg [24] argues that often strategy emerges over time as intentions run into a changing reality. Emergent strategies arise and can differ from intended strategy.

Emergent strategy is an unplanned set of actions or behavior that develop and are consistent over time, "a realized pattern [that] was not expressly intended" in the original planning of strategy [24]. When a deliberate strategy is employed, the behavior and actions match the intended undertaking [24]. An emergent strategy develops when an organization takes a series of actions that with time turn into a consistent pattern of behavior, regardless of specific intentions. Emergent strategy implies that an organization is learning what works in practice.

With mandated change, strategic foresight is sometimes not a realizable objective. And while deliberate processes may be implemented, sometimes emergent strategies become the clear choice. This is not to suggest that emergent strategy equates to an out of control situation. For a strategy to be emergent, there must be order that becomes established, but the specific intention was not present from the beginning [24]. It would make sense that this type of strategic process might occur under the time pressure and imposed nature of a mandated regulatory change.

\subsection{HR Department as Agent of Change}

There is an expectation that the HR department acts as an agent of change [1, 25-27] in its response to internal and external demands. HR change agentry is seen as a crucial competency in today's world. Several factors make up this competency. In order to act as an agent of change, extensive research suggests HR managers to have an understanding of the relevance associated with social capital and relationship management, ethical leadership, treating the affected employee as an internal stakeholder, developing consensus among the affected stakeholders, and the role communication plays within the process [26, 28-35]. This mindset has been identified by Salamzadeh, et al. [2], who found that more attention should be paid to human resource practices for improved corporate entrepreneurship. Our literature review found the following three practices to be the predicted linchpins of successful HR strategy when responding to change imposed by an outside mandate. These practices and their relationships to employee engagement are depicted in Figure 1.

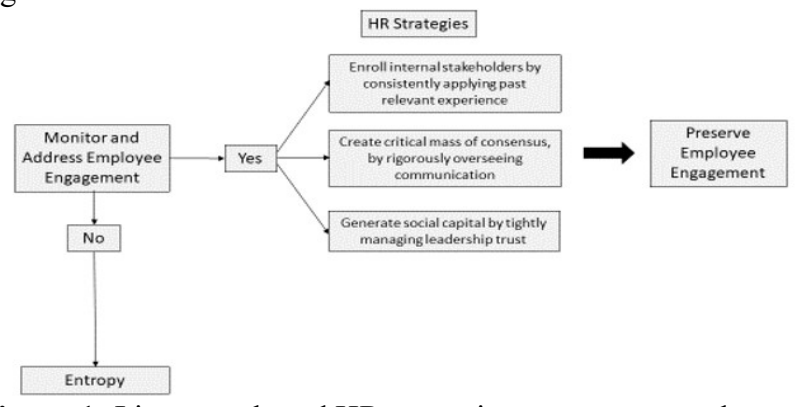

Figure 1: Literature-based HR strategies to manage employee engagement during imposed change.

\subsection{HR Strategy One: Enlist Internal Stakeholders by Consistently Applying Past Relevant Experience}

\section{Enroll Stakeholders}

There are several crucial reasons to enroll internal stakeholders in communications regarding changes. We believe that the most pertinent to this paper include involving those affected in the implementation process [28, 33]; maintaining the trust of those affected $[30,34]$ involving HR in meaningful ways (Maheshwari \& Vohra, 2015; Teo, 2002); and generating transparent disclosure to all affected parties [32].

Similar to the recruiting system tendencies for corporate entrepreneurial orientation that Salamzadeh, et al. [2] examined, when members act as participants in the development and implementation of organizational decisions, feelings of personal control of the change process increase, and there is less potential for uncertainty, with its accompanying stress reactions [33, 36, 37]. Bordia, et al. [33] further affirm that feelings of control are generated by involvement in the change. Additionally, they assert that when the change is perceived to have a large impact, it is more important to involve those effected. Such involvement is likely to increase the belief that implementation was fair and that the organization trusts its employees.

Similarly, organizational leaders are often questioned regarding the sincerity and motives behind organizational change. HR can and is often expected to act as a mediator in the relationship between decision-makers and the affected members [34]. Teo [35] contends that the HR department, through neglecting this expectation, may often be to blame for negative feelings toward leadership when it comes to implementing change. Maheshwari and Vohra [31] discuss the need for HR take the lead to build the trust of affected stakeholders in both the organization and its leaders.

Transparency (truthfully explaining the why of the change and how it affects individuals) regarding the change is thought to be a fundamental aspect of implementing change by Schnackenberg and Tomlinson [32]. They stress the importance of transparency, in part, due to the ability of organizational members to share opinions and information through electronic means.

Fjeldstad, et al. [38] assert that positive social relationships are more likely when the employee deems the company as having sufficient communication transparency. Schnackenberg and Tomlinson [32] define transparency as the "perception of received information". This includes the employee understanding and supporting the organizational norms and rules and the communication of said rules.

Ultimately, developing quality, open communication aimed at the stakeholders while including them in the implementation process may be considered the best method for controlling rumors and decreasing the fear associated with change. It 
promotes and maintains trust in the organization and its leadership.

\section{Apply Past Experience}

There may be a perception that those individuals who have dealt with many instances of structural change are better equipped to manage mandates throughout the organization. Lazar [39] suggests that HR managers who have dealt with prior organizational change develop a self-efficacy in handling change situations. Previous experience allows the manager to analyze the issue objectively and make better decisions regarding implementation.

Wang, et al. [40] agree with Lazar's view and expand the conversation to state that effective change is also affected by traits within the organization's culture. They suggest that some organizations are "crisis-prone," negatively influencing implementation. Conversely, those organizations who employ experienced crisis management teams within HR are not considered "crisis-prone" and are likely to handle change better.

Further, Maheshwari \& Vohra [31] and Goksoy [30] stress that HR managers must also maintain the organization's strategic initiatives and mission during their task of implementing the change. In the case of implementation of the FLSA requirement, HR managers must strike a balance between managing compensation changes and acting as stewards of the organization's mission.

\subsection{HR Strategy Two: Create Critical Mass of Consensus by Rigorously Overseeing} Communication

\section{Create Consensus}

Literature defines consensus based upon employee perception and having either positive or negative leanings. Junni, et al. [28] argue that the employee must believe that the manager (in this case HR) identifies with the employee's issue in order for positive employee perception to be possible. They found that if this belief is not present, then the affected employee is likely to feel constrained within their role, interfering with their ability to complete assigned tasks.

Maheshwari and Vohra [31] believe that positive perception is created when HR encourages organizational leader's involvement in change implementation. They recommend that HR include management in developing positive perception as well as working with affected employees. Additionally, HR must help leaders manage the messaging to those affected by changes.

Motivation for the change can be developed by other means as well. Goksoy [30] acknowledges that tampering with compensation may create issues with retaining employees. She further suggests that helping the employee to appreciate their role in the organization and potential for future progression, as well as helping them to understand the compensation system may increase the likelihood of their staying and supporting the change. Conveying that information requires utilizing effective communication and tailoring it toward the individual versus an entire population.

\section{Oversee Communication}

Communication is discussed at length as it relates to influencing change implementation. Two key perspectives center on positive preparation for change $[28,30,32,33]$ and preventing resistance to said change [26, 31, 34, 41, 42].

Lewis [43] alleges that, quite often, human resource departments are expected to implement new policies, systems, and/or technologies after the decision to adopt them has been made. HR is expected to play a key role in implementation, given the belief that they possess expertise to sway organizational stakeholders, or they have enhanced people skills to bring naysayers on board. The root of this belief is that human resource departments are able to effectively communicate at all levels of the organization. Lewis [43] further describes the importance of this skill in these words:

Communication is an important means by which change implementers introduce, describe, persuade, support, and evaluate changes and change processes. It is also the chief means by which those opposed to or uncertain about changes resist, question, challenge, and seek support.

Communication, then, is seen as a key HR responsibility that controls the messaging to stakeholders, leverages social capital, serves to maintain trust, and endeavors to generate a consensus. Further, implementation of a new, externally imposed mandate which is negatively perceived requires HR managers to move toward implementation even while working within employee concerns [43].

Fulmer and Chen [44] believe that today's organizations may be attempting to solve employee concerns when they do not understand the actual issue. As an illustration of this belief, there is often a gap between an organization's leadership's determination that the pay system needs to change versus how the change is understood by the parties it affects.

\subsection{HR Strategy Three: Generate Social Capital by Tightly Managing Leadership Trust}

\section{Generate Social Capital}

Bamberger and Belogolovsky [45] allege that an employee experiences feelings of being treated fairly when they discern a tight linkage between their production versus what they receive. This concept is important in understanding the generation of social capital: the shared goals, assumptions and interpersonal relationships that build trust and promote cooperative work [46], as affected by personal perception of fairness of compensation versus actual compensation. This perception is also dependent on the relationship between supervisors and those affected by compensation changes, such as those brought about by outside directives such as the FLSA mandate. The relationship is more positive when there are effective two-way channels of communication between the 
employee and their supervisor. When a higher level of trust exists, then there is potential for increased support for the change [26].

Junni, et al. [28] takes the discussion further and focuses on the role the organization has in supporting a structure for positive social relationships. And when the HR manager or department is acting openly as an organizational change agent, they are better able to help front-line managers buy in to the rationale behind specific actions, even when $\mathrm{HR}$ has no control over the change [26].

\section{Manage Leadership Trust}

There are many precursors to trust. Chughtai, et al. [29] assert that ethical leadership (a person following ethical standards and working for the common good [47]) is linked to engagement via trust in one's supervisor. When one feels their superior acts ethically, they are more engaged and display better workplace performance [32]. Chughtai [29] adds, when a superior is able to understand and convey messaging while viewed as competent by the employee, that the manager is considered to acting in an ethical manner. Goksoy [30] found that when employees believe their superiors are acting ethically, conveying the reasoning and purpose of changes is streamlined. When employees understand the rationale behind change, they tend to better trust the implementation process [30].

\section{METHOD}

This study employed semi-structured interviews with eight full-time senior human resource directors from a cross-section of large national organizations, including international healthcare companies, an international hotel chain, international technology companies, national chain restaurants, and an international non-profit organization. Semi-structured interviews selected due to the fluctuation in language used within different industries. Convenience sampling was utilized via contacts through the authors' connections via the Society for Human Resource Management (SHRM). The research was approved by the university's institutional review board. The authors are not affiliated with any of the organizations from which data was collected, and the human resource directors who provided the sample for interviewing were not privy to the questions before the interview.

Structured telephone interviews were conducted, as telephone interviews are an effective and economical method of collecting data where the sample is geographically dispersed. Telephone interviewing can be ideally suited to busy professional respondents, such as human resources managers, and timed appointments can be set up.

The human resource directors from approximately thirty organizations were sent, via email, a form requesting participation. Firms that were identified and selected are industry leaders in hospitality, technology, and healthcare. These industries were selected, due to the nature of those areas to have diverse levels within employee positions. From the contact list of responses, each respondent was asked if they would be willing to answer questions about the Fair Labor Standards Act, human resource department's reaction to mandated changes, and employee engagement at their organization via a telephone call. Each respondent was informed that the interview would take less than 30 minutes and all responses would be kept confidential. Informants were advised that if individual responses were to be reported, they would be coded and non-identifiable. Interviews occurred during August and September of 2017 three to four months prior to the December 1 mandate implementation date.

The development of the final instrument was based on the literature review and two exploratory interviews. While the interview topics were established by the authors, refinement of the questions and a search for other important topics that might have been overlooked was accomplished via two exploratory interviews. Furthermore, questions were piloted during the exploratory interviews. The exploratory interviews followed the same format as the interviews included in this study.

The established interview questions were asked of each respondent in the same order (see Appendix A). A minimum of two authors participated in each interview and a highquality speakerphone was used to conduct the interviews. Verbal consent was secured prior to continuation of the interview, and informants were made aware that their answers were being recorded but would be non-identifiable if reported. Respondents were given the option to not have the interview recorded. The interview questions were established and ordered during an exploratory interview process (see Appendix A). Questions pertained to employee engagement issues at their organization and upcoming FLSA exemption status changes. Limited probing was conducted to clarify responses to questions and to ensure valid responses were recorded by the authors. Each interview was recorded, and notes were taken by the attending authors. All notes and recordings were made available to the investigators.

At the conclusion of the phone interview, researchers clarified notes taken during the interview individually and discussed responses for consistency and to illuminate any variations in response interpretation. Recorded responses were replayed and discussed further. Following the interview, recorded responses were transcribed. With the interviews digitized, data was coded and summarized so that patterns could be identified through using frequencies of words. Word counts and thematic frequencies were identified as consistent in the data. As Kirk and Miller [48] have noted, this trail is the most assured protector of reliability in qualitative inquiry. The simple measure of usefulness is whether the research allows you to see the world as your respondents see it and allows you to think more formally about the nature of the problem before you.

Respondents were mostly male (5) and this ratio deviates from the human resource industry average, where 70 percent of human resource managers are female (Young Entrepreneur Council, 2012). All respondents had been in their current role 
for at least six years. The number of employees that each human resource manager/director oversaw was between 140 and approximately 64,000. Only three of the respondents had fewer than 1,000 employees, and multiple organizations had over 40,000 under the responsibility of the HR professionals interviewed.

The organizations were all national or international in scope, but all were headquartered in the United States. Size of the human resource departments ranged from one single HR director contrasted with the largest institution interviewed having more than 33 human resource professionals on staff.

\section{RESULTS}

\subsection{Thematic Analysis}

In the semi-structured interview method, a series of initial open-ended questions are presented, accompanied by probing queries for more detailed information, are asked of each respondent. Following McCraken's [49] process of analysis, each interview transcript was reviewed twice: once for content understanding and a second time for noting interesting observations. Observations are developed into preliminary descriptive and interpretive categories. This coding process provides the brief description of what is present in the interview. This provided the basis for examining meaningful groups. Patterns of themes are then pulled from the categories and prominent themes are identified.

Following the model in Figure 1 the investigators offer the following analysis

\section{Employee Engagement - Understanding Undone}

One of the discoveries through this research was a lack of consistency in defining and dealing with the topic of employee engagement. There was very little consistency in how companies promoted engagement. One respondent stated that "engagement is one of those topics that we're trying to figure out." Several of the companies we spoke with "hoped that employees were engaged," but did "little outside of pay" to encourage engagement as they perceived the issue. There were some efforts by companies to better understand employee engagement. Two of the organizations we spoke with conducted surveys to acquire a sense of employee sentiment. Another stated that they maintained an open-door policy to "better know" employees, which in turn would promote engagement. Annual salary surveys and action-planning were being examined more closely in light of the anticipated FLSA changes. Most companies did not want to focus on pay/financial metrics when addressing engagement related issues.

One informant suggested that employee engagement could not be handled by broad measures and needed to be handled in a personalized way. Other comments we heard echoed this mindset. Phrases such as "we don't manage their engagement" and "employment engagement is in the role" emphasized an individual focus on this topic. Some of the responses felt deflective in regard to the topic and provided a sense that any understanding a company had in the past might be changed by this regulatory shift. Despite the hands-off approach by some of the HR managers we spoke with, the majority seemed to have a desire to understand engagement and develop practices to promote it.

Actual Emergent HR Strategy vis-à-vis Organizational Effect - Reducing the Pain for the Offended or Outraged Specific to the organizations we interviewed, the repercussions of the change were also creating questions. While this change was viewed as a positive push to treat employees industrywide consistently and fairly, the individuals we spoke to had concerns about how to be the best steward of company resources while adjusting to the FLSA mandated changes. Perceived "unfairness" in changes to employee compensation, limiting of time allowed to accomplish work, decreases in flexibility, and the short turn-around time for implementing changes created stressful situations for most of those we spoke to about the changes. A lack of time for strategizing, communicating, and implementing new procedures was viewed as challenging.

\section{Status Quo/Status No}

In addition to the compensation concerns, morale and employee engagement were top concerns for the human resource professionals to whom we spoke. While they were not hearing many comments from employees facing a change in status, the managers we spoke to perceived this as an important issue. There was a strong sense of apprehension about shifts in morale that might result from changes in classifications within these organizations, and how these would impact not only employee but manager engagement. There was a perception that for employees who were functioning as managers the idea of moving from exempt to non-exempt would be demoralizing, even if the amount of wages/salary remained the same. Respondents feared that formerly salaried employee who now had to "record time" or "punch a clock" might view the change as demeaning, and that those formerly in the exempt category might view the new categorization as being a demotion.

There was obvious status and prestige with exempt status. One manager went so far as to describe the perception within his organization as "professional versus nonprofessional." In addition, there was a perceived loss of autonomy or flexibility with the employees who had discussed this with their HR managers. One employee had suggested that this shift placed a value on "time working rather than quality of work." HR managers were also receiving questions based on confusion as to how hours worked might be calculated, especially for employees who had not been locked into a 40-hour week but would need to function in that way going forward. The consensus was that employee engagement would suffer as a result of the mandated changes.

Actual Emergent HR Strategy vis-à-vis Enrolling Internal Stakeholders by Applying Past Relevant Experience Regarding Change

While most managers we spoke to felt "under the gun" with this policy change, we did speak to a few managers who were 
not as concerned. Some, especially those with prior experience from previous policy changes, were not as worried. One informant stated that this "wasn't a big deal...especially when compared to ACA," highlighting the difficulties created through the Affordable Care Act and its implementation. The tension was also, understandably, less for companies with fewer employees being affected by the changes.

When asked about informal conversations with other HR professionals, much of the information provided was proactive in thought, but reactive in implementation. While communication with acquaintances in the HR field were not usually policy related, most of the HR professionals we spoke to had asked about the current situation and bounced ideas off of each other. Though strategy and best practices for dealing with regulatory change was discussed, most HR professionals we spoke to or who were involved in these informal discussions, were not acting on the ideas and strategies they discussed.

Actual Emergent HR Strategy vis-à-vis Industry Effect and Reevaluation of Models (or "Ripping the Band-Aid Off")

From an industry standpoint, the threat was easily identified in terms of compensation and hours worked. In a "doublewhammy of sorts," some managers saw the compensation dollars as definitely increasing for the industry. However, concern over decreases in the number of hours employees could work was also a concern. For example, a previously exempt employee working 45 hours a week would be limited to 40 hours per week or would have to have increased compensation for the overtime hours, a decision most organizations we spoke with were not inclined to pursue. In addition, bonus compensation structures were also going to have to be reexamined. One manager stated that this mandate made their bonus structure "irrelevant." Most of those we spoke to were very concerned about the time available for the industry to find best practices. One informant stated that it was like "ripping the Band-Aid off," and that a gradual easing of the policy would have been more tolerable.

Outside of employee hours and compensation, there was some sentiment that basic business models would need to be reevaluated. Matters such as hours of operation and location of businesses would need further scrutiny under this policy. There was also some concern about the structure of organizational management hierarchies, as some managers would, or could quickly, outprice themselves for positions.

\section{Do "They" Know How Much This Will Hurt?}

While many of our informants felt that change was needed and that these shifts corrected some perceived inequities, there was significant frustration with the HR professionals we interviewed, rooted in wonder about the regulatory thought process in implementing this drastic of a change in the industries. The perceived extreme level of change in such a short period of time seemed ill-conceived to most of the managers to whom we spoke. The opportunity of this mandated situation was evident to those interviewed but was not typically viewed positively. The tendency was to view this as radical change. Even the situation appeared disruptive, several HR professionals identified this obligation as a time to observe processes and better position the organization. Despite this opportunity, fear of upending current business practices obscured this possibility.

\section{Actual Emergent HR Strategy vis-à-vis Ceating a Critical Mass of Consensus by Rigorously Overseeing Communication}

Communication...Eventually - Reactive vs. Proactive For all of the concern about the changes and implementation of new strategies, the managers we interviewed were involved in copious preparation activities. Approaches to handling the changes held some overlap, but we heard a diverse number of priorities for those working toward the necessary changes. Examination of employee classifications and discussions about reclassifications was a common starting point for several of the organizations, along with salary schedule evaluations and industry salary comparisons. Communication was also a preparation discussion item, yet few had formalized the communication process or had a strategy for communicating the changes laid out in detail. Some were having difficulty in coming up with a clear strategy on not only how, but with whom to communicate specifically.

One informant said the communication element was difficult, "because how do we get our head around everything?" Most of the individuals we spoke with had a desire to be as transparent as possible during the process. However, some organizations were still mired in discussions about classification or other issues, and so information that was available for communication to the institution was very limited. The tactics for dealing with organizational communication for this change were varied. One HR manager stated that there had not been a dedicated conversation about that topic and stated that they felt unprepared for communicating the information about the change. A couple of the managers we spoke with were very focused on communication to senior members of the organization but had done very little to reach out to the entire organization, or even specifically to those that would be affected by the exempt/nonexempt status change. Others we spoke to provided details about plans for communication, including town halls, newsletters, informational videos, and individual conversations. However, upon probing about these techniques, very few individuals had moved on these ideas, despite the fact that the mandate was a couple of months away at the time of most of the interviews.

As described above, strategies for communication were also being evaluated and were perceived as benefiting the organization going forward. Whether though new initiatives, such as town halls or instructional videos, or just assessing and improving current communication methods, a renewed focus on the communication strategy was viewed positively. 
Actual Emergent HR Strategy vis-à-vis Generate Social Capital by Tightly Managing Leadership

\section{Impact on HR Practices - Too Much of a Good Thing}

From a managerial perspective, the process and planning for this mandated change highlighted some key practice improvements for our informants. While one individual stated that it would likely not impact HR practices and that they "just go along with the flow" of the regulation, most of those we spoke to provided evidence that these changes would impact their organizational strategies moving forward. At the very least, this process forced examination of employee classifications and compensation packages. It forced an examination into new ways to reward employees and make sure they felt valued. Updating compensation packages and ensuring that employment practices mirror organizational culture were benefits of this reassessment.

Specific to employee classifications, several of the organizations were making pushes to standardize job descriptions and really define "what makes a specific position." Several of those interviewed found outdated depictions of positions, and they were glad to reevaluate and updated those descriptions. Several felt that this process created some strategic opportunities for new positions that could benefit the organization.

\section{DISCUSSION}

This paper explored the primary concerns of human resource departments in several industries as they pertained to the proposed FLSA mandate. Literature-based HR strategies for managing employee engagement during mandated change were identified and informed through the interview data collected. This research indicates that additional strategies for managing imposed changes can complement those currently proposed in the discipline. Specifically, reevaluation of current employee classification structures or models for evaluative process arose from the analysis. In addition, a strategic push to use this mandated change as an opportunity for beneficial change was discovered. However, these considerations of progressive change for the organizations may work best when the disruption is minimized. Information collected from professionals involved in the efforts to handle the rollout of the mandate yielded perceived issues regarding employee status, communication importance and difficulties, and a need to rethink organizational and HR departments' planning in reacting to the mandate. While organizational responses to the proposed mandate differed in some areas, there were several commonalities in concerns about the new FLSA guidelines. These new discoveries for practice and their relationships to employee engagement are depicted in Figure 2.

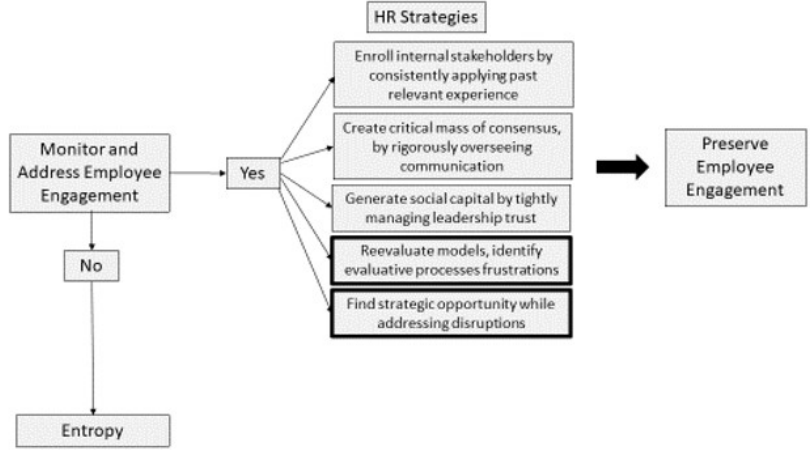

Figure 2: Data-based HR strategies to manage employee engagement during imposed change.

Overall sentiments depicted the mandate as a substantial change in practice. While there was common opinion that some change was needed, the perceived policy change was viewed as too drastic. Implementation was going to be complicated for many of the organizations, whether that difficulty resulted from current organizational practices, compensation and bonus structures, or employee morale challenges. Theoretically, the process of evaluating and reevaluating models and processes is an interesting element. Future research may investigate best practices for introducing and reworking various models for preserving employee engagement during organizational change.

In addition to changes in compensation and policy, this study has identified that morale was a focus of concern for those interviewed. The perception of a change in classification would be perceived as a demotion for those moving into the non-exempt classification. Despite the fact that some employees would move up in classification, this did not offset the apprehension of the HR professionals we interviewed.

An interesting finding in this study was the critical need for communication in this policy change process, but there were varied levels of preparedness and different strategies for implementing a communication flow to those in the organizations. Interestingly, most of the communication stream taking place was upwards, toward organizational executives, while formal communication channels elsewhere in the organization were not prevalent. Most of the HR professionals we spoke with had clear intentions to communicate across the organization and some clever approaches to create transparency in the communication process were mentioned. However, most had not moved to take action on a clear strategy of communication across the entire organization.

This study provides critical factors to consider for a large-scale change and implementation in HR policy due to sweeping regulatory changes. The ability to communicate changes with constituents, manage resources available for implementation to HR employees, care for morale and cultural repercussions, and demonstrate compensation fairness are fundamental starting points for handling this type of regulatory shift and are 
important practical implications for HR processes. In the face of change, HR professionals and departments should ensure that a transparent communication flow is established, taking into account the organizational culture and trying to preserve it. Future studies may be able to longitudinally see the effects of implementation of communication strategies for this this type of regulatory implementation. Being upfront about the reasons for the change, what the change will look like in the organization, and why those change decisions are made should be an imperative for an organization facing similar situations to the FLSA changes.

\section{REFERENCES}

[1] Ulrich, D. (1998). A new mandate for human resources. Harvard Business Review, 76(1), 124-135.

[2] Salamzadeh, A., Tajpour, M., \& Hosseini, E. (2019). Corporate entrepreneurship in University of Tehran: does human resources management matter? International Journal of Knowledge-Based Development, 10(3), 276-292.

[3] Tajpour, M., Hosseini, E., \& Moghaddm, A. (2018). The Effect of Managers Strategic Thinking on Opportunity Exploitation. Scholedge International Journal of Multidisciplinary \& Allied Studies, 5(2), 68-81.

[4] VanSchenkhof, M., Houseworth, M. \& Smith, S. (2017). Fair labor standard mandate: How do higher education human resource departments react? International Journal of Business Administration, 8(5), 36-45.

[5] Kumar M., D, \& Pandya, S. (2012). Leveraging technology towards HR excellence. Information Management and Business Review, 4(3), 205-216.

[6] Henson, R. (2009) 21st Century Human Capital Management: Adapting to the Demands of Change. USA: An IHRIM Press Book, Oracle Corporation, Redwood Shores.

[7] McKeown, M. (2016). The Strategy Book, 2nd edition. Pearson Education Limited, Edinburgh Gate, UK.

[8] Martin, G. and Reddington, M. (2009). Reconceptualising absorptive capacity to explain the e-enablement of the HR function (e-HR) in organizations. Employee Relations, 31(5), 515-537.

[9] Arrowsmith, J. \& Parker, J. (2013). The meaning of 'employee engagement' for the values and roles of the HRM function. The International Journal of Human Resource Management, 24(14), 2692-2712.

[10] Chamberlain, Kaufman, \& Jones (2007). FLSA Home Page.

[11] Gillis, Ellis \& Baker, Inc. (2015). DOL proposes changes to FLSA white collar exemption rules.

[12] National Law Review (2017). U.S. District court invalidates pending FLSA rules.

[13] Kahn, W. A. (1990). Psychological conditions of personal engagement and disengagement at work. The Academy of Management Journal, 33(4), 692-724.

[14] Maslach, C., Schaufeli, W. B. \& Leiter, M.P. (2001). Job burnout. Annual Review of Psychology, 52(1), 397-422.

[15] Shuck, B. \& Wollard. K. (2010). Employee engagement and HRD: A seminal review of the foundations. Human Resource Development Review, 9(1), 89-110.

[16] Saks, A. M. (2006). Antecedents and consequences of employee engagement. Journal of Managerial Psychology, 21, 600-619.
[17] Albrecht, S.L., Bakker, A.B., Gruman, J.A., Macey, W.H. and Saks, A.M. (2015). Employee engagement, human resource management practices and competitive advantage: An integrated approach, Journal of Organizational Effectiveness: People and Performance, 2(1), 7-35.

[18] Aktar, A. and Pangil, F. (2018). Mediating role of organizational commitment in the relationship between human resource management practices and employee engagement: Does black box stage exist? International Journal of Sociology and Social Policy, 38(7-8), 606-636.

[19] Harter, J. K., Schmidt, F. L., \& Hayes, T. L. (2002). Businessunit-level relationship between employee satisfaction, employee engagement, and business outcomes: a meta-analysis. Journal of Applied Psychology, 87(2), 268-79.

[20] Salanova, M., Agut, S. \& Peiró, J. M. (2005). Linking organizational resources and work engagement to employee performance and customer loyalty: the mediation of service climate. Journal of Applied Psychology, 90(6), 1217-27.

[21] Towers P. (2003). Working Today: Understanding What Drives Employee Engagement. Stamford, CT: Towers Perrin Talent Report.

[22] Rynes, S. L., Gerhart, B. \& Minette, K. A. (2004). The importance of pay in employee motivation: Discrepancies between what people say and what they do. Human Resource Management, 43(4), 381-394.

[23] Locke, E. A., Feren, D. B., McCaleb, K. N. \& Denny, A. T. (1980). The related effectiveness of four methods of motivating employee performance. In: Proceedings of an international conference on changes in the nature and quality of working life. Duncan, K. D., Gruneberg, M. M. \& Wallis, D. (Eds.), pp: 363388, Great Britain: John Wiley \& Sons Ltd.

[24] Mintzberg, H. (1994) Of strategies, Deliberate and Emergent. Strategic Management Journal, 6, 257-72.

[25] Caldwell, R. (2001). Champions, adapters, consultants and synergists: The new change agents in HRM. Human Resource Management Journal, 11(3), 39-52.

[26] Kim, S. \& Ryu, S. (2011). Social capital of the HR department, HR's change agent role, and HR effectiveness: Evidence from South Korean firms. The International Journal of Human Resource Management, 22(8), 1638-1653.

[27] Storey, J. (1992). Developments in the Management of Human Resources. London, UK: Oxford Blackwell.

[28] Junni, P., Sarala, R. M., Tarba, S. Y., Liu, Y. \& Cooper, C. L. (2015). Guest editors' introduction: The role of human resources and organizational factors in ambidexterity. Human Resource Management, 54(S1).

[29] Chughtai, A., Byrne, M. \& Flood, B. (2015). Linking ethical leadership to employee well-being: The role of trust in supervisor. Journal of Business Ethics, 128(3), 653-663.

[30] Goksoy, A. (2015). The Impact of Human Resource Management Practices on Employee Readiness for Change during Mergers and Acquisitions. Argumenta Oeconomica Cracoviensia, 11, 47-62.

[31] Maheshwari, S. \& Vohra, V. (2015). Identifying critical HR practices impacting employee perception and commitment during organizational change. Journal of Organizational Change Management, 28(5), 872-894.

[32] Schnackenberg, A K. \& Tomlinson, E. C. (2016). Organizational transparency: A new perspective on managing trust in 
organization-stakeholder relationships. Journal of Management, 42(7), 1784-1810.

[33] Bordia, P., Hobman, E., Jones, E., Gallois, C. \& Callan, V. J. (2004). Uncertainty during organizational change: Types, consequences, and management strategies. Journal of Business and Psychology, 18(4), 507-532.

[34] Hollenbeck, J R. \& Jamieson, B. B. (2015). Human capital, social capital, and social network analysis: Implications for strategic human resource management. The Academy of Management Perspectives, 29(3), 370-385.

[35] Teo, S. T. T. (2002). Effectiveness of a corporate HR department in an Australian public-sector entity during commercialization and corporatization. International Journal of Human Resource Management, 13(1), 89-105.

[36] Locke, E. A. \& Schweiger, D. M. (1979). Participation in decision-making: One more look. Research in Organizational Behavior, 1(10), 265-339.

[37] Spector, P. E. (1986). Perceived control by employees: A metaanalysis of studies concerning autonomy and participation at work. Human relations, 39(11), 1005-1016.

[38] Fjeldstand, Ø. D., Snow, C. C., Miles, R. E. \& Lettl, C. (2012). The architecture of collaboration. Strategic Management Journal, 33(6), 734-750.

[39] Lazar, A. (1999). Deceiving oneself or self-deceived? On the formation of beliefs "under the influence. Mind, 108, 265-290.

[40] Wang, J., Hutchins, H. M. \& Garavan, T. N. (2009). Exploring the strategic role of human resource development in organizational crisis management. Human Resource Development Review, 8(1), 22-53.

[41] DiFonzo, N. \& Bordia, P. (1998). A tale of two corporations: managing uncertainty during organizational change. Human Resource Management, 37(3-4), 295-303.
[42] Isabella, L. A. (1990). Evolving interpretations as a change unfolds: How managers construe key organizational events. Academy of Management Journal, 33(1), 7-41.

[43] Lewis, L. (2014). Change Management. In: Meeting the challenge of human resource management: A communication perspective. Miller, V. D. \& Gordon, M. E. (Eds.), pp: 134-144. New York, US: Routledge.

[44] Fulmer, I. S.\& Chen, Y. (2014). How communication affects employee knowledge of and reactions to compensation systems. In: Meeting the challenge of human resource management: A communication perspective. Miller, V. D. \& Gordon, M. E. (Eds.), pp: 134-144. New York, US: Routledge.

[45] Bamberger, P. \& Belogolovsky, E. (2010). The impact of pay secrecy on individual task performance. Personnel Psychology, 63(4), 965-996.

[46] Dekker, P. \& Uslaner, E.M. (2001). Introduction. In: Social Capital and Participation in Everyday Life. Dekker, P. \& Uslaner, E.M. (Eds.). London, UK: Routledge.

[47] Bisk Education (2017). Villanova University: What is ethical leadership.

[48] Kirk, J., \& Miller, M. (1986). Reliability and validity in qualitative research. Beverly Hills, CA, US: Sage Publication.

[49] McCracken, G. (2011). The long interview. Newbury Park, CA, US: Sage Publications.

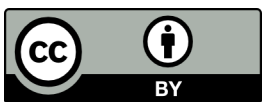

(C) 2021 by the Matthew Vanschenkhof, Matthew Houseworth, Lorin Walker and Scott Smith. Submitted for possible open access publication under the terms and conditions of the Creative Commons Attribution (CC $\quad$ BY) license (http://creativecommons.org/licenses/by/4.0/). 